\title{
Performance of low temperature Microbial Fuel Cells (MFCs) catalyzed by mixed bacterial consortia \\ Olga Tkach ${ }^{1}$, Thangavel Sangeetha ${ }^{1}$, Spiridonova Maria ${ }^{3}$, Aijie Wang $^{1,2, *}$
}

\begin{abstract}
Microbial Fuel Cells (MFCs) are a promising technology for treating wastewater in a sustainable manner. In potential applications, low temperatures substantially reduce MFC performance. To better understand the effect of temperature and particularly how bioanodes respond to changes in temperature, we investigated the current generation of mixed-culture and pure-culture MFCs at two low temperatures, $10^{\circ} \mathrm{C}$ and $5^{\circ} \mathrm{C}$. The results implied that the mixed-culture MFC sustainably performed better than the pure-culture (Shewanella) MFC at $10^{\circ} \mathrm{C}$, but the electrogenic activity of anodic bacteria was substantially reduced at the lower temperature of $5^{\circ} \mathrm{C}$. At $10^{\circ} \mathrm{C}$, the maximum output voltage generated with the mixed culture was $540-560 \mathrm{mV}$, which was $10 \%-15 \%$ higher than that of Shewanella MFCs. The maximum power density reached $465.3 \pm 5.8 \mathrm{~mW} / \mathrm{m}^{2}$ for the mixed culture at $10^{\circ} \mathrm{C}$, while only $68.7 \pm 3.7$ $\mathrm{mW} / \mathrm{m}^{2}$ was achieved with the pure culture. It was shown that the anodic biofilm of the mixed culture MFC had a lower overpotential and resistance than the pure culture MFC. Phylogenetic analysis disclosed the prevalence of Geobacter and Pseudomonas rather than Shewanella in the mixed culture anodic biofilm, which mitigated the increase of resistance or overpotential at low temperatures.
\end{abstract}

Keywords: microbial fuel cell; psychrophilic bacteria; Shewanella; low temperature; bioelectrochemical 
* Corresponding author. E-mail: waj0578@ hit.edu.cn (Aijie Wang)

\section{Introduction}

Microbial Fuel Cells (MFCs) have garnered tremendous research attention over the last decade due to their low energy cost during wastewater treatment. In MFCs, the microorganisms at the anode convert chemical energy into electrical energy by oxidizing organic compounds present in wastewater and use the anode as the final electron acceptor (Torres et al., 2009). Although a great deal of technical development of MFC reactors at laboratory scale has been achieved, the construction and operation of larger-scale systems still face inherent challenges before they can become an efficient and economical alternative to the current commercialized wastewater treatment technologies (Logan, 2008). Temperature fluctuation is one of several problems that must be solved in order to achieve the successful operation of large-scale MFCs. Optimal temperatures for MFCs enable shorter start-up times for reaching reproducible voltage generation and better anode performance, since anodic biofilm formation is faster and enzymes are more active. However, practical application of MFCs in wastewater treatment requires operation at ambient temperatures (Ahn and Logan, 2010; Cheng et al., 2011; Michie et al., 2011; Patil et al., 2010). Low temperature is considered a vital factor affecting the electrochemical properties of anoderespiring microbes, and is an important factor in achieving stable current generation in practical MFC applications, and changes in many related key properties such as microbial anode potential and internal resistance can bring about a drastic change in their performance (Wang et al., 2010a, 2010b).

Recent research has implied that at lower temperatures the reactor must generate less electric current (Liu et al., 2012). Usually it is suggested that starting an MFC at moderate temperatures (around $22^{\circ} \mathrm{C}$ ) is possible for practical operation in wastewater treatment, but a long lag phase would occur during start up under these conditions (Min et al., 2008). MFC operation at low temperature $\left(15^{\circ} \mathrm{C}\right)$ has not been successful, with low power output being obtained even after several loadings. Adding certain auxiliary chemicals, such as trehalose, could maintain anode biofilm activity at $0^{\circ} \mathrm{C}$ (Linji et al., 2014). However, Jadhav and Ghangrekar (2009) have reported enhanced MFC performance at low $\left(10^{\circ} \mathrm{C}\right)$ rather than at high temperatures $\left(20-35^{\circ} \mathrm{C}\right)$. With decrease in temperature, the growth of methanogens was 
suppressed and a larger fraction of the substrate was available to the electrogenic population, resulting in an increase in current and CE. Therefore, there are still gaps remaining in the understanding of bioelectrochemical property changes concerning anodic microbial communities under low temperature conditions.

To date, discrete entities of bacterial species of genus Geobacter (Richter et al., 2008), Enterobacter (Rezaei et al., 2009), Shewanella (Firer-Sherwood et al., 2008; Watson et al., 2010) and Bacillus (Nimje et al., 2009) have been tested with respect to generation of electrical current or maximization of the power output of MFCs. Recently, MFCs inoculated by mixed microbial communities have garnered much attention owing to their stability, robustness due to nutrient adaptability, stress resistance, and general tendency to produce higher current densities than those with pure cultures (Lanthier et al., 2008). A study conducted by Larrosa-Guerrero et al. (2010), in single and double-chambered MFCs using mixed bacterial consortia at $4^{\circ} \mathrm{C}$, revealed that MFCs can be successfully operated at low temperatures and that psychrophilic bacteria were present in the mixed consortia. These results support the proposition that employing mixed cultures in reactors will be more beneficial and advantageous than pure cultures.

In order to understand the differences in electric current production at low temperature by a mixed-culture system compared to pure cultures, it is important to study the behavior of the system individually and synergistically using a pure culture as control. Such comparisons are needed to provide insights into the effects of mixed cultures on power production at low temperature. The aim of this study was to evaluate MFC performance in terms of overpotential and internal resistance at the low environmental temperatures of 10 and $5^{\circ} \mathrm{C}$. The anode performance of the MFCs was evaluated by polarization measurements, electrochemical impedance spectroscopy and cyclic Voltammetry tests.

\section{Materials and methods}

\subsection{Microbial fuel cell construction and operation}

Single-chambered MFCs were constructed of polypropylene with an effective working volume of $110 \mathrm{~mL}$ (Wang et al., 2010c; Liu et al., 2012). A photograph of the reactor is shown in Fig. 1. The anode was a carbon fiber brush $(40 \mathrm{~mm}$ in diameter and $40 \mathrm{~mm}$ in length; T700-12K, Toray Industries Co. Ltd., Japan). The cathode was made of a piece of 
carbon cloth (W0S1002, CoTech Co., Ltd.) with an effective area of $19.6 \mathrm{~cm}^{2}$. The waterfacing side of the cathode was coated with carbon black (Vulcan XC-72) and catalyst (0.5 $\mathrm{mg} / \mathrm{cm}^{2} \mathrm{Pt}$ ), and the air-facing side consisted of four PTFE diffusion layers (Cheng et al., 2006; Logan et al., 2007). Electrodes were connected by insulated copper wire with external load resistance of $1000 \Omega$. A Ag/AgCl reference electrode (type 217, XianRen Industries Co., Shanghai, China) was installed into the anodic chamber to aid in the electrochemical measurements. For pure culture experiments, the polypropylene tubes were sterilized before use.

\subsection{Inoculation and startup of MFCs}

The activated sludge for this research as seed bacterial culture was procured from Harbin Wenchang Wastewater Treatment Plant (Wang et al., 2014) and was mixed with an acetate medium for electricity generation. The culture medium for the mixed culture was prepared in phosphate buffer solution (PBS) containing $2 \mathrm{~g} / \mathrm{L}$ of acetate. The MFC startup was conducted at $10^{\circ} \mathrm{C}$ initially. Half of the microbial culture broth was replaced with fresh medium every five days to maintain maximum metabolic activity. PBS medium consisted of $\mathrm{NH}_{4} \mathrm{Cl} 0.62$ $\mathrm{g} / \mathrm{L}, \mathrm{KCl}, 0.26 \mathrm{~g} / \mathrm{L}, \mathrm{NaH}_{2} \mathrm{PO}_{4} 4.9 \mathrm{~g} / \mathrm{L}, \mathrm{Na}_{2} \mathrm{HPO}_{4} 9.15 \mathrm{~g} / \mathrm{L}$, mineral solution $12.5 \mathrm{~mL} / \mathrm{L}$ and Wolfe's vitamin solution $5 \mathrm{~mL} / \mathrm{L}$ ( $\mathrm{pH} 7.0$ ). When the voltage production dropped to $50 \mathrm{mV}$, half of the medium was replaced by fresh medium. The MFCs were considered ready for steady-state operation when their voltage output was stable after three cycles of medium replacement. After achieving stable bioelectrochemical performance at $10^{\circ} \mathrm{C}$, continuous operation was carried out at $5^{\circ} \mathrm{C}$. All temperature conditions of 10 and $5^{\circ} \mathrm{C}$ in this experiment were controlled by a constant temperature incubator (BI-250A, STIK, USA) as described in a previous study (Kong et al., 2014).

Shewanella sp. ALL-2 was extracted from the mixed bacterial culture in the activated sludge (Tkach et al., 2014), and was used to assemble pure-culture MFCs as control reactors in this study. The PBS medium for pure culture MFCs was prepared and stored in sterile containers before inoculation, and all instruments and solutions were exposed to UV to avoid contamination. The cultured Shewanella sp. were inoculated into MFCs, and the same operation for mixed-culture MFCs was carried out at the same time at low temperatures.

\subsection{Electrochemical analysis}


The cell voltage was measured automatically (one data point per minute) through a data acquisition system DAS 5020; Jiehan Technology Corporation. The electrical power density $P$ for MFCs in the batch-fed mode was calculated as Eq. (1)

$$
P=\frac{U I}{\text { Area }}
$$

where $U(\mathrm{~V})$ is the voltage between anode and cathode, $I(\mathrm{~A})$ is the current in, and Area is anode area, equal to $19.625 \mathrm{~cm}^{2}$.

Linear sweep voltammetry (LSV) was performed using a potentiostat-galvanostat model CHI 440, CH Instrument Inc., Austin, TX, USA. The voltage and current were recorded by LSV at a scan rate of $1 \mathrm{mV} / \mathrm{sec}$, and power was calculated by multiplying voltage and current. The current density and power density were calculated from the area of the cathode $\left(19.625 \mathrm{~cm}^{2}\right)$. A three-electrode system in the anode compartment was used for analysis of electrochemical response (Cai et al., 2016). Polarization curves were obtained once every 20 min by varying the resistance of the MFC circuit in a descending order. The electrochemical impedance spectroscopy (EIS) experiments were performed at the end of the experiment with "Zahner TM IM6ex" potentiostat-AC frequency analyzer equipment, and the results were analyzed using the "Thales1" software. Impedance measurements were conducted with a frequency range from $10 \mathrm{MHz}$ to $100 \mathrm{kHz}$ using a sinusoidal perturbation with amplitude of 5 $\mathrm{mV}$. In addition, two-electrode experiments were conducted for evaluation of the ohmic internal resistance of the MFCs. The anode resistance and the total ohmic resistance are represented as the Zre (Real) axis of the Nyquist plot. The resistance to anode charge transfer was determined using circle fit software (Hutchinson et al., 2011), using the diameter of the semicircle of impedance data in the Nyquist plot.

Cyclic Voltammetry (CV) was performed using a potentiostat (PGSTAT 128N, Metrohm Autolab, Netherlands) (Hong et al., 2011). The anode was used as the working electrode, the cathode as the counter electrode and the $\mathrm{Ag} / \mathrm{AgCl}$ electrode as the reference electrode. $\mathrm{CVs}$ were conducted from $-0.6 \mathrm{~V}$ as initial anode potential to $+0.6 \mathrm{~V}$ as final potential for 4 cycles at a scan rate of $1 \mathrm{mV} / \mathrm{sec}$. The first derivative of the $\mathrm{CV}$ was derived by plotting the slope of each $\mathrm{CV}$ data point (DI/DE) vs the potential, and was determined at high frequencies where the impedance data crosses the axis.

\subsection{Phylogenetic analysis}


The process of identification of the dominant electrochemically active microbes consisted of: dispersion of the samples; isolation of the developed colonies and isolate identification by SDS-PAGE (sodium dodecyl sulphate-polyacrylamide gel electrophoresis) and 16S rRNA gene analysis (Liu et al., 2013). Microbial samples obtained from the well-developed biofilm on the anode of MFCs were used for the identification of predominant bacteria capable of bioelectricity generation. The samples were then spread on solidified agar medium plates with iron-containing medium with $\mathrm{NaHCO}_{3} 2.5 \mathrm{~g} / \mathrm{L}, \mathrm{NH}_{4} \mathrm{Cl} 1.5 \mathrm{~g} / \mathrm{L}, \mathrm{KH}_{2} \mathrm{PO}_{4} 0.6 \mathrm{~g} / \mathrm{L}, \mathrm{KCl}$ $0.1 \mathrm{~g} / \mathrm{L}$, yeast extract $0.01 \mathrm{~g} / \mathrm{L}$, ferric citrate $12.28 \mathrm{~g} / \mathrm{L}$, and acetate $0.82 \mathrm{~g} / \mathrm{L}$, and $\mathrm{pH}$ was adjusted to 6.8. The screening for the most dominant and genetically identical isolates was done by SDS-PAGE and protein spectra (i.e., translation profiles).

The bacterial 16S rRNA gene clone libraries were constructed by using universal primer sets 27F (50-AGAGTTTGATCC TGGCTCAG-30) and 1492R (50GGTTACCTTGTTACGACTT-30). PCR-amplification was performed following the conditions: 5 min of denaturation at $94^{\circ} \mathrm{C}$, followed by 35 cycles at $94^{\circ} \mathrm{C}$ for $45 \mathrm{sec}, 55^{\circ} \mathrm{C}$ for $45 \mathrm{sec}$ and $72^{\circ} \mathrm{C}$ for $90 \mathrm{sec}$, with a final extension at $72^{\circ} \mathrm{C}$ for $10 \mathrm{~min}$. The PCR products were purified on a $1 \%$ agarose gel, extracted with a UNIQ-10 gel-extraction kit (Shanghai Sangon Biological Engineering Technology \& Services Co., Ltd., Shanghai, China), then they were ligated to vector pMD19 and cloned into E. coli DH5a competent cells in compliance with the manufacturer's protocol. One hundred plasmids containing positive inserts from these samples were sequenced using an ABI 3730XL sequencer (Applied Biosystems, Foster, CA) using $27 \mathrm{~F}$ primer. Then $16 \mathrm{~S}$ rRNA gene sequences were analyzed using the "BLASTN" (http://www.ncbi.nlm.nih.gov/blast) search tools and "EzTaxon" server (Chun et al., 2007). Alignments with different 16S rRNA gene sequences from GenBank were performed using "Clustal X" 1.8 .3 with default settings. The phylogenetic characteristics were analyzed with "MEGA" version 6.0 software, and distances were calculated with help of the "Kimura 2" parameter distance model. A phylogenetic tree was built by the neighbor-joining method. Each dataset was bootstrapped over 1000 times (Tamura et al., 2007).

\section{Results and discussion}

\subsection{MFC performances at low temperatures}


The voltages produced by different reactors at two temperatures are shown in Fig. 2. At $10^{\circ} \mathrm{C}$, the voltage of reactors increased to the maximum level during the feeding and after 8 10 days it decreased to less than $100 \mathrm{mV}$ for both pure and mixed bacterial cultures. The voltage of the mixed-culture MFC gradually increased from 500 to $565 \mathrm{mV}$ after each feed replacement; whereas a stable output voltage generation of $500 \mathrm{mV}$ was achieved by the control pure culture MFC. These results indicated that there was an ongoing process of formation of a mature biofilm on the anode. On the 30th day the temperature was reduced to $5^{\circ} \mathrm{C}$ in order to investigate the impacts of low temperature on electricity generation and culture vitality. Electrogenic activities of all MFCs were substantially reduced at $5^{\circ} \mathrm{C}$. There was a $12 \%$ reduction of the peak output voltage compared to that of $10^{\circ} \mathrm{C}$. For the pureculture control MFC, the duration of peak output voltage was noticeably reduced from 10 to 5 days, indicating a reduction of output duration time at low temperatures. Before every feed replacement, the COD removals were up to $90 \%-95 \%$, which led to a drop of output power at the end of each batch cycle in Fig. 2.

For the mixed-culture $\mathrm{MFC}$ at $10^{\circ} \mathrm{C}$, the open circuit voltage $(\mathrm{OCV})$ was $327 \pm 11 \mathrm{mV}$ (Table 1). When the temperature was reduced from 10 to $5^{\circ} \mathrm{C}$, the OCV decreased to $99 \pm 8$ $\mathrm{mV}$, while the OCV measured was $168 \pm 11 \mathrm{mV}$ in the control MFC of the pure culture at $10^{\circ} \mathrm{C}$, and the $\mathrm{OCV}$ was also reduced to $110 \pm 5 \mathrm{mV}$ at $5^{\circ} \mathrm{C}$. High OCV was obtained possibly due to the fact that anode-respiring bacteria can accumulate a charge on the electrode without electron transport (Esteve-Núñez et al., 2008), but electron loss was less effective in the mixed culture than in the pure culture. Lower temperature decreased the OCV. The decrease in working voltage in the low current region indicated larger activation losses; hence the MFC with Shewanella had greater energy losses than the mixed-culture MFC. This can also serve as substantiation for the dramatic change in OCV and maximum power density of the mixed culture MFC after temperature reduction from 10 to $5^{\circ} \mathrm{C}$. In a study on the ability of bacteria to accumulate charge, it was found that G. sulfurreducens had enough electronstorage capacity to eliminate the need to respire over a period of $8 \mathrm{~min}$ when there was no electron acceptor available (Esteve-Núñez et al., 2008).

For the pure culture at $10^{\circ} \mathrm{C}$, after the output voltage reached $128 \pm 10 \mathrm{mV}$, the power density reached a maximum of $83.7 \pm 4.0 \mathrm{~mW} / \mathrm{m}^{2}$ (Fig. 3). The short-circuit current density $\left(I_{\mathrm{scc}}\right)$ attained a value of $1.72 \pm 0.12 \mathrm{~A} / \mathrm{m}^{2}$ (Table 1). When temperature was reduced from 10 
to $5^{\circ} \mathrm{C}$, the maximum power density was reduced to $68.7 \pm 3.7 \mathrm{~mW} / \mathrm{m}^{2}$ at the voltage of $69 \pm 5$ $\mathrm{mV}$, and $I_{\mathrm{scc}}$ was $0.95 \pm 0.05 \mathrm{~A} / \mathrm{m}^{2}$. However, the mixed culture showed a much higher output power density at $10^{\circ} \mathrm{C}$. The voltage reached values as high as $232 \pm 7 \mathrm{mV}$, and the power density reached $465.3 \pm 5.8 \mathrm{~mW} / \mathrm{m}^{2}$. $I_{\mathrm{scc}}$ was $3.06 \pm 0.56 \mathrm{~A} / \mathrm{m}^{2}$. When the temperature was reduced from 10 to $5^{\circ} \mathrm{C}$, the maximum power density was only $61.6 \pm 3.5 \mathrm{~mW} / \mathrm{m}^{2}$ when the voltage was substantially decreased to $65 \pm 4 \mathrm{mV}$, and $I_{\mathrm{scc}}$ was $1.49 \pm 0.72 \mathrm{~A} / \mathrm{m}^{2}$. The results implied that the MFC with the mixed culture performed better than the pure culture MFC at $10^{\circ} \mathrm{C}$, but a lowering of the temperature to $5^{\circ} \mathrm{C}$ substantially reduced the electrogenic activity of both mixed culture and pure culture.

\subsection{Electrode characteristics}

As shown in the Table 2, values of $R_{\text {in }}$ were respectively calculated for individual electrodes with the same equation $\left(R_{\mathrm{in}}=R_{\mathrm{S}}+R_{\mathrm{p}}\right)$. Values of $R_{\mathrm{S}}$ and $R_{\mathrm{p}}$ were obtained through the "ZSime" program based on the analysis described in previous studies (He et al., 2009). Setting the circuit module let the program return a table with values of $R_{\mathrm{s}}$ and $R_{\mathrm{p}}$. Nyquist plots for the pure-culture MFC at $10^{\circ} \mathrm{C}$ showed that the internal resistance $R_{\text {in }}$ reached $46 \Omega$ for the anode, and it was approximately $25 \Omega$ for the cathode (Fig. 4). At $5^{\circ} \mathrm{C}$, there was a significant rise in the anode internal resistance up to $152 \Omega$; but a relatively stable resistance was presented by the mixed culture MFC. The control MFC with pure culture had an anode internal resistance of $31 \Omega$ at $10^{\circ} \mathrm{C}$, but this increased to $37 \Omega$ at $5^{\circ} \mathrm{C}$, and the cathode internal resistances were all approximately $44 \Omega$ at both $10^{\circ} \mathrm{C}$ and $5^{\circ} \mathrm{C}$. This indicated that the anode internal resistance was quite sensitive to temperature. Moreover, a huge increase in the anode internal resistance occurred in the pure culture MFC when the temperature was reduced from $10^{\circ} \mathrm{C}$ to $5^{\circ} \mathrm{C}$. On the other hand, at the cathode, low temperature led to a relatively small increase in cathode internal resistance for all MFCs, but the pure-culture cathode internal resistance still varied much more than for the mixed culture.

The anodes of mixed-culture MFCs also achieved lower charge transfer resistances than pure-culture MFCs at $10^{\circ} \mathrm{C}$ (Fig. 4). The mixed-culture charge transfer resistances of $1.5 \pm 1 \Omega$ and $3.5 \pm 1 \Omega$ were achieved at $10^{\circ} \mathrm{C}$ and $5^{\circ} \mathrm{C}$ respectively. However, the anode for the pure culture had a slightly larger charge transfer resistance of $20 \pm 1 \Omega$ at $10^{\circ} \mathrm{C}$, but a greatly increased charge transfer resistance of $77 \pm 3 \Omega$ at $5^{\circ} \mathrm{C}$. The anode charge transfer resistance is 
a useful tool for evaluating the stability of the anode biofilm. Liu et al. (2005) operated batchfed MFCs to evaluate the effects of reactor configuration, temperature and ionic strength on power generation. They reported that temperature can be a vital factor affecting the biological activities of bacteria in the biofilm, which in turn may cause an impact on the charge transfer ability and internal resistance of the electrodes. So, these factors were found to be interrelated.

\subsection{Cyclic voltammetry analysis of anode}

Cyclic voltammetry (CV) data are shown in Fig. 5 for the voltage overpotential output of the anodic biofilm of both the reactors at $10^{\circ} \mathrm{C}$ and $5^{\circ} \mathrm{C}$. Fig. 5a shows that the voltage overpotential for the mixed culture at $10^{\circ} \mathrm{C}$ was $300 \mathrm{mV}$, whereas it was $400 \mathrm{mV}$ for the pure culture. Fig. 5b shows no significant peak voltage outputs. Thus, it was evident that the mixed-culture anode was better than the pure-culture one, with a low overpotential. This aspect was supported by Selembo et al. (2010), where they have suggested that electrodes that produce the lowest overpotentials can be selected for bioelectrochemical reactors. Similar findings were reported by Sangeetha et al. (2015), where a Ni electrode that produced the lowest overpotential was chosen for upflow bioelectrochemical reactors.

\subsection{Microbiological identification of dominant strain in mixed-culture MFC}

The 16S rRNA gene libraries for clones of the MFC anode biofilm with active sludge gave 59 operational taxonomic units (OTUs), based on a random sample of 100 clone sequences. Ribotypes were identified phylogenetically and were grouped according to the type or class (for Protebacteria) using a global sequence alignment for taxonomic approach. The total ratio for this phylogenetic group was calculated (Fig. 6), and in the result, the dominant phyla were Geobacter psychrophilus, Pseudomonas caeni, Simplicispira psychrophila, Comamonas badia and Geobacter chapellei. To determine which bacterial strains played the role of key species in the mixed culture MFC, we conducted purification for the predominant species in the mixed culture.

Mechanisms proposed for electron transfer by Shewanella sp. have included direct transfer by cell-surface contact (Marsili et al., 2008), self-produced mediators/electron shuttles (Lanthier et al., 2008; Biffinger et al., 2007), and bacterial nanowires (Goby et al., 2006). Some of these can operate and enrich in psychrophilic conditions. Liu et al. (2012, 2013) constructed and operated two single-chambered MFCs with mixed culture at $15^{\circ} \mathrm{C}$ and 
$25^{\circ} \mathrm{C}$. They reported that the MFC with psychrophilic bacteria was better in performance, with low anodic resistance and better electricity generation, and this condition was attributable to a better enrichment of psychrophilic bacteria like Shewanella psychrophila and Geobacter psychrophilus in the anodic biofilm. So, we also confirmed that the reason for the better performance of the mixed-culture MFC compared to the pure-culture MFC in this study may be due to the enrichment of psychrophilic bacteria.

In this study, phylogenetic analysis disclosed the prevalence of Geobacter and Pseudomonas, rather than Shewanella, in the mixed-culture anodic biofilm at low temperatures. Exo-electrogenic bacteria like Geobacter, Shewanella and Pseudomonas have been identified by Geochip-based functional gene analysis in the bioelectrochemical systems by Liu et al. (2010, 2012). Geobacter sp. have been widely studied due to their electro-active ability for current generation in MFCs (Bond and Lovley, 2003; Liu et al., 2004). It was reported by Nevin et al. (2005) that Geobacter psychrophilus is an iron-reducing psychrophilic bacteria which can be grown at low temperatures from $4^{\circ} \mathrm{C}-10^{\circ} \mathrm{C}$. Pseudomonas were also found to be one of the dominant bacteria in the anodic biofilm of the mixed-culture MFC in this study. Though Pseudomonas sp. were abundantly found in the bioelectrochemical systems, they were low-power-density producing microbes. However, they were considered to generate self-produced mediators like pycocyanin, which can be used by other microbes for anodic respiration. So, the above-mentioned studies give evidence that the psychrophilic bacteria in the anodic biofilm of the mixed-culture MFCs were electroactive, which mitigated the increase of resistance or overpotential at low temperatures.

Actually, low temperatures $\left(4^{\circ} \mathrm{C}\right.$ or $\left.10^{\circ} \mathrm{C}\right)$ will lead to a long start-up process for MFCs due to slow growth of anode-respiring bacteria. Research has pointed out that low temperature MFCs did not produce appreciable power unless they were first operated at $30^{\circ} \mathrm{C}$ before being switched to the lower temperatures (Cheng et al., 2011). In this study, Geobacter and Pseudomonas were the most dominant species under low temperature conditions, but other anaerobic bacteria were retarded at low temperature compared with their microbial abundance at room temperature. Similar results were also obtained in microbial electrolysis cells, which enriched the dominant populations belonging to $\delta$-Proteobacteria and $\gamma$-Proteobacteria at both room temperature and low temperature, but Bacteroidetes were reduced by $50 \%$ when temperature decreased to $4^{\circ} \mathrm{C}$ (Lu et al., 2011). 
Since only acetate was used as a carbon source, however, a relatively high functional and phylogenetic diversity of microorganisms was successfully formed in the mixed-culture biofilm (Liu et al., 2010). In recent studies of mixed cultures, microbial community analysis showed that planktonic bacteria with exoelectrogenic ability contributed to a lower system resistance, which was positive for electron transfer for anode biofilms (Wang et al., 2010a). Lately, the contribution of bacteria without the ability for anode respiration in bioelectrochemical systems has been discussed. It was found that the part of the microbial communities that did not participate in extracellular electron transfer was maintained in the anaerobic niche of electrode biofilms, where they could provide labile products for electroderespiring bacteria (Liu et al., 2016a, 2016b). The diversity of the community may be maintained through utilization of compounds excreted by electrogenic bacteria, or by growth on the biomass of other cells by nonacetate-utilizing bacteria (Liu et al., 2010). This is consistent with the better performance of mixed-culture than pure-culture MFCs at low temperatures. Therefore, characterization of the mixed microbial communities in different MFC environments and analysis of the roles of the different microbial groups in substrate oxidation and power production are also needed in the future.

\section{Conclusions}

In this research work, the performance of single-chamber MFCs has been evaluated at the low temperatures of $5^{\circ} \mathrm{C}$ and $10^{\circ} \mathrm{C}$. Although lower temperature decreased electrogenic bacterial activity, the mixed-culture exhibited a higher electricity output capability than the pure-culture MFC, which led to a lower internal resistance and overpotential for mixedculture MFC anodic performance compared to the pure-culture MFC at $10^{\circ} \mathrm{C}$. It was found that the enrichment of Pseudomonas, Geobacter etc. in the mixed culture could maintain microbial functions or interspecies cooperation, which supported sustainable electron generation and anodic activities. However, a substantial performance decline occurred with low output voltage for both mixed-culture and pure-culture MFCs when the temperature was further reduced to $5^{\circ} \mathrm{C}$.

\section{Acknowledgments}


This research was supported by the National Science Foundation for Distinguished Young Scholars (No. 51225802), the National Natural Science Foundation of China (No. 51578534), the "Hundred Talents Program" of the Chinese Academy of Sciences, and by Project 135 of the Chinese Academy of Sciences (No. YSW2013B06).

\section{References}

Ahn, Y., and Logan, B.E., 2010 Effectiveness of domestic wastewater treatment using microbial fuel cells at ambient and mesophilic temperatures. Bioresour. Technol. 101 (2), 469-475.

Biffinger, J.C., et al., 2007 A biofilm enhanced miniature microbial fuel cell using Shewanella oneidensis DSP10 and oxygen reduction cathodes. Biosens. Bioelectron. 22(8), 1672-1679.

Bond, D.R., and Lovley, D.R., 2003 Electricity production by Geobacter sulfurreducens attached to electrodes. Appl. Environ. Microbol. 69(3), 1548-1555.

Cai, W., et al., 2016 Enhanced hydrogen production in microbial electrolysis cell with 3D self-assembly nickel foam-graphene cathode. Biosens. Bioelectron. 80, 118-122.

Cheng, S., et al., 2006 Increased performance of single-chamber microbial fuel cells using an improved cathode structure. Electrochem. Com. 8(3), 489-494.

Cheng, S., et al., 2011 Electricity generation of single-chamber microbial fuel cells at low temperatures. Biosens. Bioelectron. 26 (5), 1913-1917.

Chun, J., et al., 2007 EzTaxon: a web-based tool for the identification of prokaryotes based on 16S ribosomal RNA gene sequences. Int. J. Syst. Evol. Microbiol. 57(10), 2259-2261.

Esteve-Núñez, A., et al., 2008 Fluorescent properties of c-type cytochromes reveal their potential role as an extracytoplasmic electron sink in Geobacter sulfurreducens. Environ. Microbiol. 10(2), 497-505.

Firer-Sherwood, M., et al., 2008 Electrochemical interrogations of the Mtr cytochromes from Shewanella: opening a potential window. J. Biol. Inorg. Chem. 13 (6), 849-854.

Gorby, Y.A., et al., 2006 Electrically conductive bacterial nanowires produced by Shewanella oneidensis strain MR-1 and other microorganisms. Proc. Natl. Acad. Sci. U.S.A.103(30), 11358-11363.

He, Z., et al., 2009 Exploring the use of electrochemical impedance spectroscopy (EIS) in microbial fuel cell studies. Energ. Environ. Sci. 2(2), 215-219. 
Hong, Y., et al., 2011 Adaptation to high current using low external resistances eliminates power overshoot in microbial fuel cells. Biosens. Bioelectron. 28 (1), 71-76.

Hutchinson, A.J., et al., 2011 Analysis of carbon fiber brush loading in anodes on startup and performance of microbial fuel cells. J. Power Sources. 196 (22), 9213-9219.

Jadhav, G.S. and Ghangrekar, M.M. 2009 Performance of microbial fuel cell subjected to variation in $\mathrm{pH}$, temperature, external load and substrate concentration. Bioresour Technol. 100, 717-723.

Kong D., et al., 2014 Effect of temperature switchover on the degradation of antibiotic chloramphenicol by biocathode bioelectrochemical system. J. Environ. Sci-China. 26(8), 1689-1697.

Lanthier, M., et al., 2008 Growth with high planktonic biomass in Shewanella oneidensis fuel cells. FEMS Microbiol. Lett. 278(1), 29-35.

Larrosa-Guerrero, A., et al., 2010 Effect of temperature on the performance of microbial fuel cells. Fuel. 89(12), 3985-3994.

Linji, X., et al., 2014 Trehalose enhancing microbial electrolysis cell for hydrogen generation in low temperature $\left(0^{\circ} \mathrm{C}\right)$. Bioresource Technology. 166 (2014), 458-463

Liu, H., et al., 2005 Power generation in fed-batch microbial fuel cells as a function of ionic strength, temperature, and reactor configuration. Environ Sci Technol. 39, 5488-5493.

Liu, H., et al., 2004 Production of electricity during wastewater treatment using a single chamber microbial fuel cell. Environ. Sci. Technol. 38, 2281-2285.

Liu, L., et al., 2012 Anodic biofilm in single-chamber microbial fuel cells cultivated under different temperatures. Int. J. Hydrogen Energy. 37(20), 15792-15800.

Liu, L., et al., 2013 Double-chamber microbial fuel cells started up under room and low temperatures. Int. J. Hydrogen Energy. 38, 15574-15579.

Liu, W., et al., 2010 Geochip-based functional gene analysis of anodophilic communities in microbial electrolysis cells under different operational modes. Environ. Sci. Technol. 44, 7729-7735.

Liu, W., et al., 2012 Characterization of microbial communities during anode biofilm reformation in a two-chambered microbial electrolysis cell (MEC). J. Biotechnol.157, 628-632.

Liu, W., et al., 2016a Microbial electrolysis contribution to anaerobic digestion of waste activated sludge, leading to accelerated methane production. Renew. Energ. 91: 334-339 
Liu W., et al. 2016b Microbial network for waste activated sludge cascade utilization in an integrated system of microbial electrolysis and anaerobic fermentation. Biotechnol. Biofuels. 9, 83-98

Logan, B.E., 2008 Microbial Fuel Cells. Wiley, Hoboken, USA.

Logan, B.E., et al., 2007 Graphite fiber brush anodes for increased power production in aircathode microbial fuel cells. Environ. Sci. Technol. 41(9), 3341-3346.

Lu L., et al., 2011 Hydrogen production, methanogen inhibition and microbial community structures in psychrophilic single-chamber microbial electrolysis cells Energy Environ. Sci. 4, 1329-1336

Marsili, E., et al., 2008 Shewanella secretes flavins that mediate extracellular electron transfer. Proc. Natl. Acad. Sci. U.S.A.105(10), 3968-3973.

Michie, I.S., et al., 2011 The influence of psychrophilic and mesophilic start-up temperature on microbial fuel cell system performance. Energy Environ. Sci. 4 (3), 1011-1019.

Min, B., et al., 2008 Importance of temperature and anodic medium composition on microbial fuel cell (MFC) performance. Biotechnology Letters. 30(7), 1213-1218

Nevin, K.P., et al., 2005 Geobacter bemidjiensis sp. nov. and Geobacter psychrophilus sp. nov., two novel Fe (III)-reducing subsurface isolates. Int. J. Syst. Evol. Microbiol. 55(4), 1667-1674.

Nimje, V.R., et al., 2009 Stable and high energy generation by a strain of Bacillus subtilis in a microbial fuel cell. J. Power Source. 190, 258-263.

Patil, S.A., et al., 2010 Electroactive mixed culture biofilms in microbial bioelectrochemical systems: The role of temperature for biofilm formation and performance. Biosens. Bioelectron. 26 (2), 803-808.

Rezaei, F., et al., 2009 Simultaneous cellulose degradation and electricity production by Enterobacter cloacae in a microbial fuel cell. Appl. Environ. Microbiol. 75(11), 36733678.

Richter, H., et al., 2008 Electricity generation by Geobacter sulfurreducens attached to gold electrodes. Langmuir. 24(8), 4376-4379.

Sangeetha, T., et al., 2015 Cathode material as an influencing factor on beer wastewater treatment and methane production in a novel integrated upflow microbial electrolysis cell (Upflow-MEC). Int J. Hydrogen Energy.41(4), 2189-2196.

Selembo, P.A., et al., 2010 Hydrogen production with nickel powder cathode catalysts in 
microbial electrolysis cells. Int. J. Hydrogen Energy. 35(2), 428-437.

Tamura, K., et al., 2007 MEGA4: molecular evolutionary genetics analysis (MEGA) software version 4.0. Mol. Biol. Evol.24(8), 1596-1599.

Tkach, O., et al., 2014 Performance analysis of microbial fuel cells with different exoelectrogens at low temperature. Applied Mechanics Materials. 733, 189-194.

Torres, C.I., et al., 2009 Selecting anode-respiring bacteria based on anode potential: phylogenetic, electrochemical, and microscopic characterization. Environ. Sci. Technol. 43(24), 9519-9524.

Wang, A.J., et al., 2010a Key factors affecting microbial anode potential in a microbial electrolysis cell for $\mathrm{H}_{2}$ production. Int. J. Hydrogen Energy. 35,13481-13487.

Wang, A.J., et al., 2010b Reduced internal resistance of microbial electrolysis cell (MEC) as factors of configuration and stuffing with granular activated carbon. Int. J. Hydrogen Energy. 35, 13488-13492.

Wang, A.J., et al., 2010c A rapid selection strategy for an anodophilic consortium for microbial fuel cells. Bioresour Technol. 101, 5733-5735.

Wang, L., et al., 2014 Enhanced biohydrogen production from waste activated sludge in combined strategy of chemical pretreatment and microbial electrolysis. Int. J. Hydrogen Energy. 39, 11913-11919

Watson, V.J., and Logan, B.E., 2010 Power production in MFCs inoculated with Shewanella oneidensis MR-1 or mixed cultures. Biotechnol. Bioeng. 105, 489-498. 

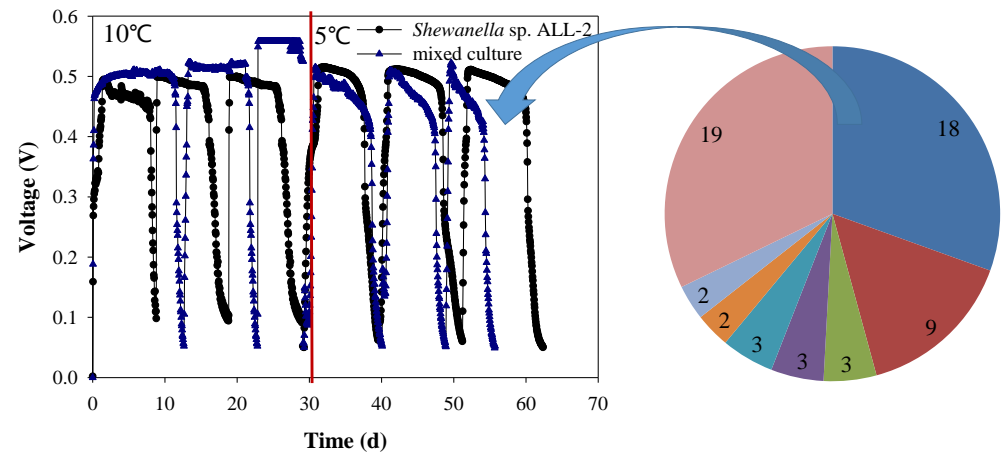

- Geobacter psychrophilus $\mathrm{P} 35(\mathrm{~T})$

- Pseudomonas caen $\mathrm{HY}-14(\mathrm{~T})$

- Simplicispira psychrophila LMG 5408(T)

- Comamonas badia IAM 14829(T)

- Geobacter chapellei 172(T)

- Comamonas nitrativorans $23310(\mathrm{~T})$

$\square$ Paludibacter propionicigenes WB4(T)

wother 
Table 1 Cell performance under different operational temperatures

\begin{tabular}{llllll}
\hline Reactor & $\begin{array}{l}\text { Temp. } \\
\left({ }^{\circ} \mathrm{C}\right)\end{array}$ & $\begin{array}{l}\text { OCV } \\
(\mathrm{V})\end{array}$ & $\begin{array}{l}\text { Maximum power density } \\
\left(\mathrm{mW} / \mathrm{m}^{2}\right)\end{array}$ & $\begin{array}{l}I_{\mathrm{scc}} \\
\left(\mathrm{A} / \mathrm{m}^{2}\right)\end{array}$ & $\begin{array}{l}\text { Voltage at maximum power } \\
\text { density }(\mathrm{mV})\end{array}$ \\
\hline Mixed culture & 10 & $327 \pm 11$ & $465.3 \pm 5.8$ & $3.06 \pm 0.56$ & $232 \pm 7$ \\
& 5 & $99 \pm 8$ & $61.6 \pm 3.5$ & $1.49 \pm 0.72$ & $65 \pm 4$ \\
Pure culture & 10 & $168 \pm 11$ & $83.7 \pm 4.0$ & $1.72 \pm 0.12$ & $128 \pm 10$ \\
& 5 & $110 \pm 5$ & $68.7 \pm 3.7$ & $0.95 \pm 0.05$ & $69 \pm 5$ \\
\hline
\end{tabular}

Error bar: The data were measured in at least three replicate batch operations.

OCV: open circuit voltage; $I_{\text {scc }}$ : short-circuit current density

Table 2 Electrode resistances of the examined MFCs $(\Omega)$

\begin{tabular}{lllllll}
\hline Reactor & Temp. & $R_{\mathrm{s}}$ & & $R_{\mathrm{p}}$ & $R_{\text {in }}$ \\
\cline { 3 - 6 } & $\left({ }^{\circ} \mathrm{C}\right)$ & Anode & Cathode & Anode & Cathode & (an./cath.) \\
\hline Mixed culture & 10 & 29 & 35 & 2 & 9 & $31 / 44$ \\
& 5 & 35.5 & 36 & 1.5 & 8 & $37 / 44$ \\
Pure culture & 10 & 44 & 23 & 2 & 2 & $46 / 25$ \\
& 5 & 150 & 35 & 2 & 2 & $152 / 37$ \\
\hline
\end{tabular}

$R_{\mathrm{s}}$ : solution resistance (ohmic resistance); $R_{\mathrm{p}}$ : Polarization resistance (charge transfer resistance); $R_{\mathrm{in}}$ : internal resistance 


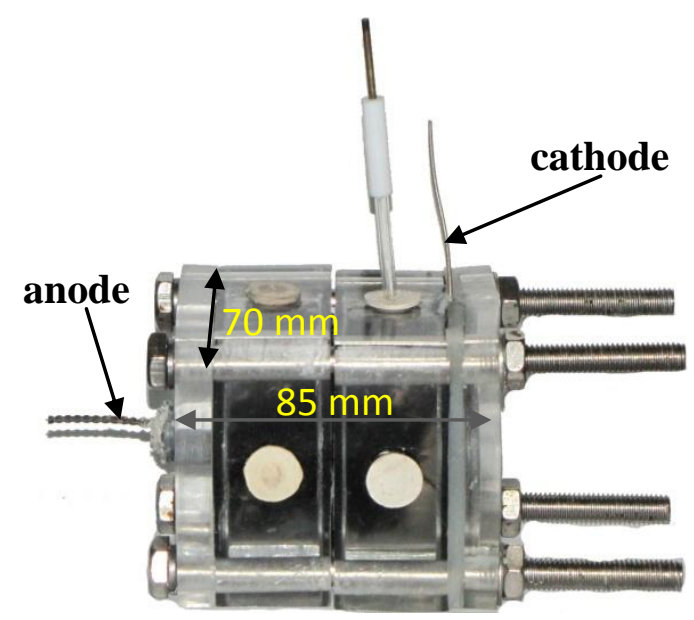

Fig. 1 Photograph of the Microbial fuel cell used in this work. 


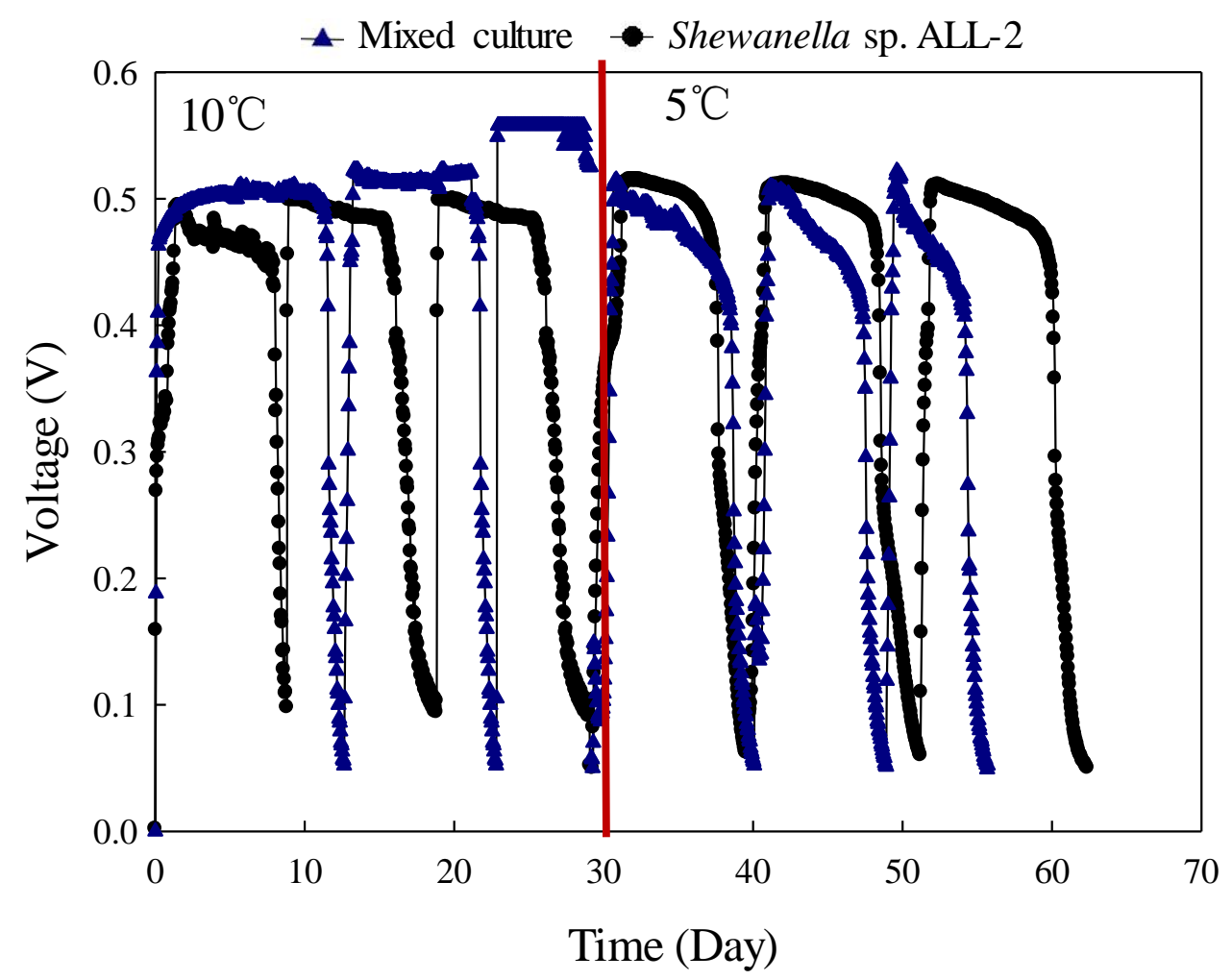

Fig. 2 Output voltage generation of MFCs operated under different temperatures (1000 $\Omega$ ). The switch of the operational temperature was carried out on day 30 and is indicated by the vertical red line. 
- Mixed culture

Shewanella sp. ALL-2
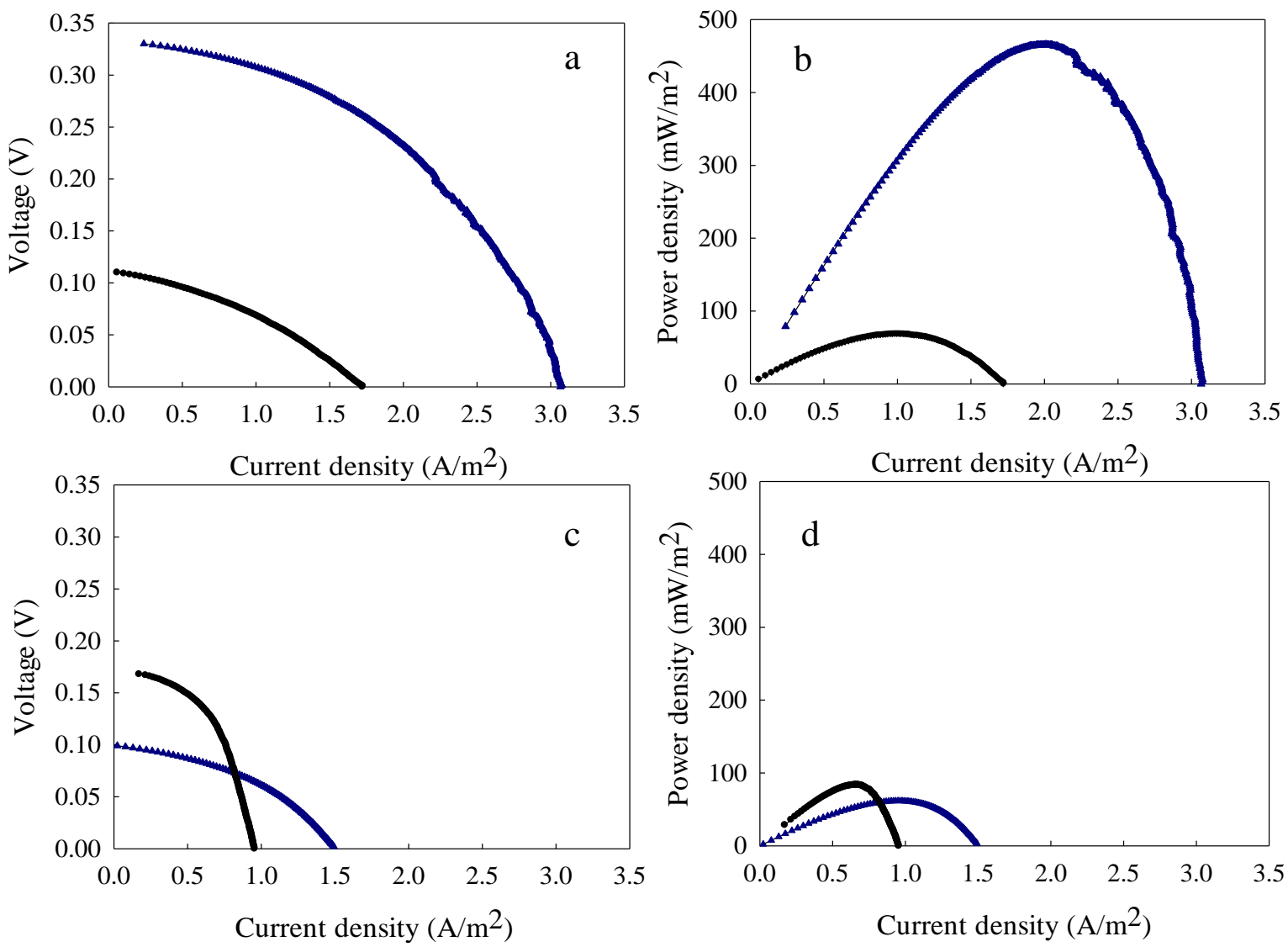

Fig. 3 Polarization curve and power density curve for different reactors under two operating temperatures: $(\mathrm{a}, \mathrm{b}) 10^{\circ} \mathrm{C},(\mathrm{c}, \mathrm{d}) 5^{\circ} \mathrm{C}$. 

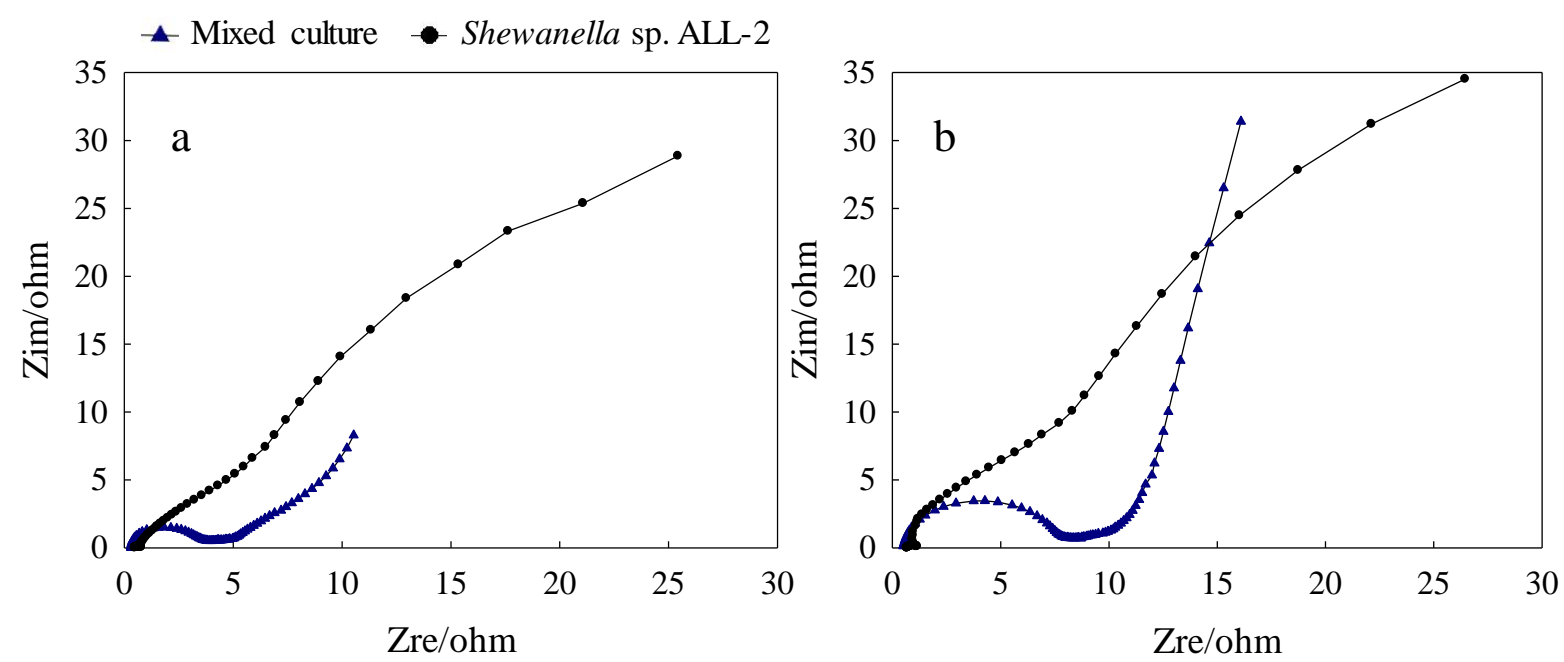

Fig. 4 The Nyquist plots of anode impedance spectra for reactors at $10^{\circ} \mathrm{C}$ (a) and $5^{\circ} \mathrm{C}$ (b) 

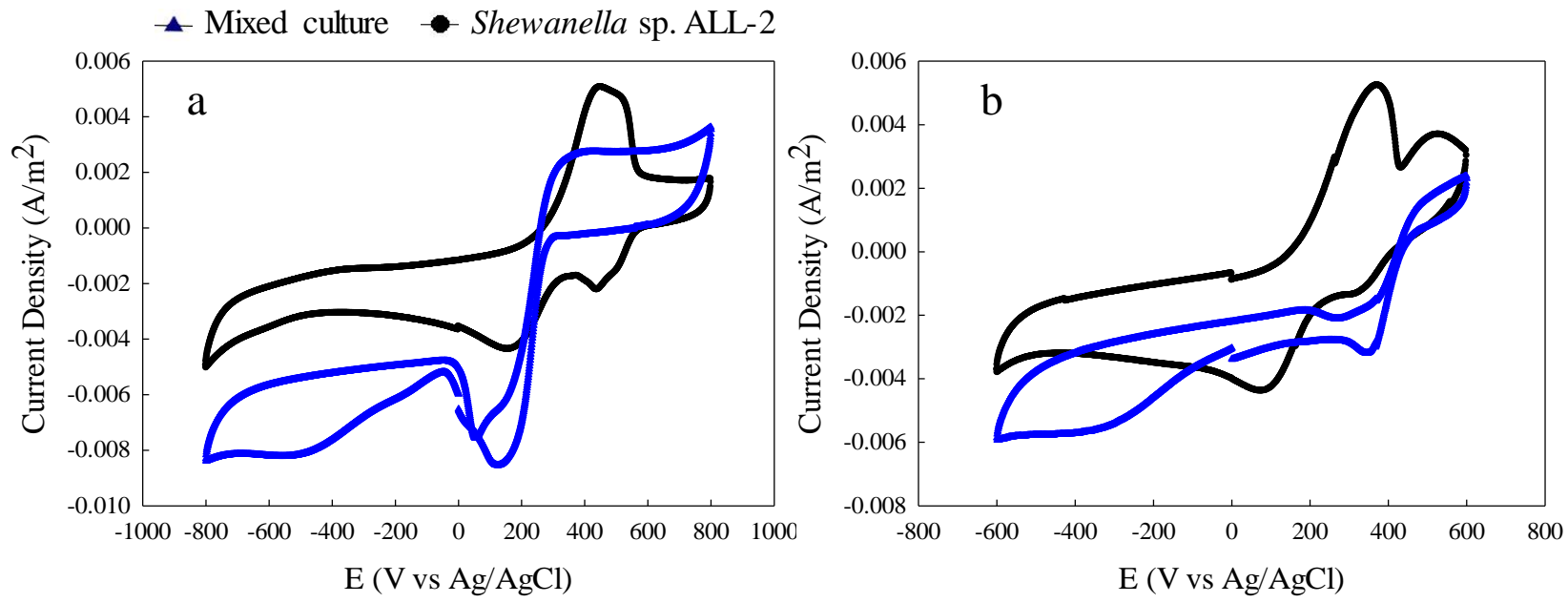

Fig. 5 The cyclic voltammograms of anodes operated at (a) $10^{\circ} \mathrm{C}$ and (b) $5^{\circ} \mathrm{C}$ 


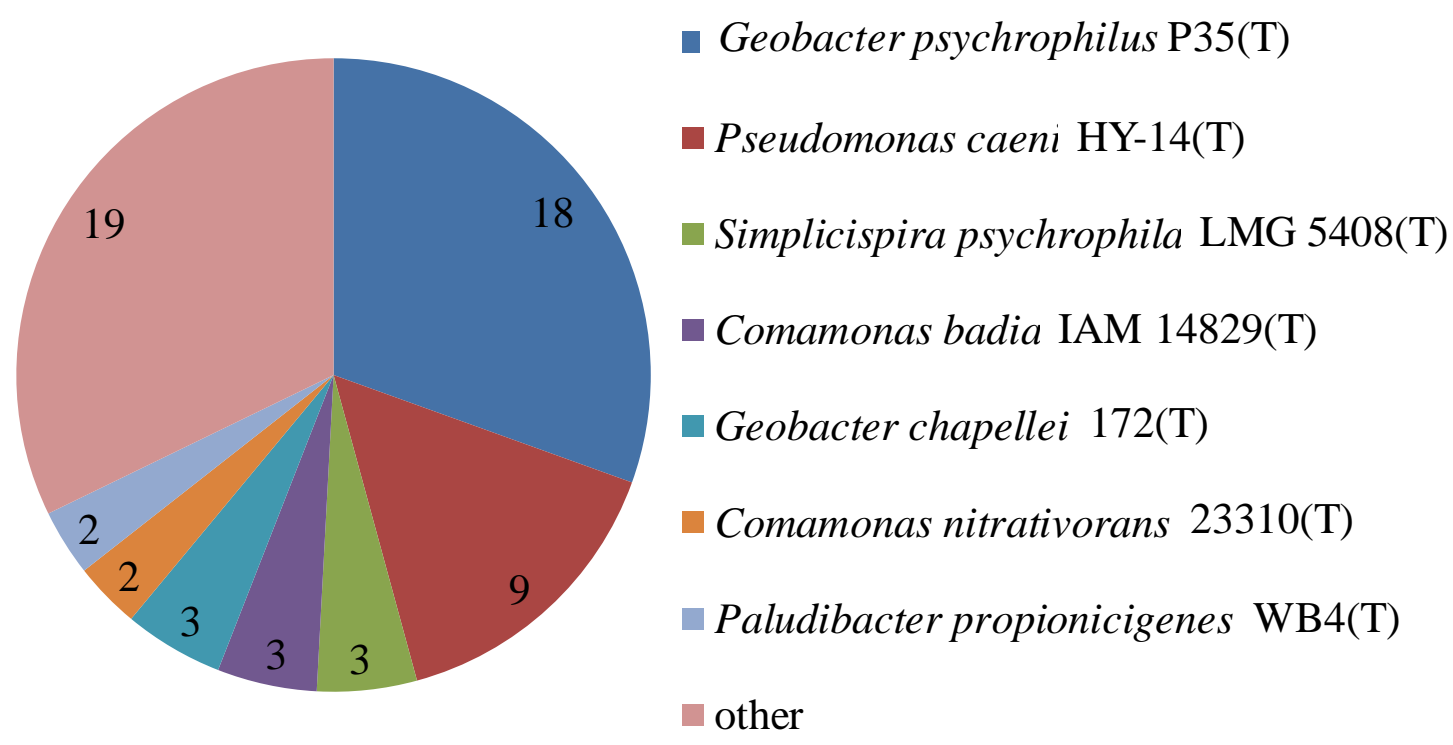

Fig. 6 Phylum distributions in the anode biofilm 